\title{
Strategies for Teaching Undergraduate Business Students Data Analytics
}

\author{
J. Kirk Atkinson \\ Gordon Ford College of Business \\ Western Kentucky University \\ 1906 College Heights Blvd \\ Bowling Green, Kentucky 42101-1058 \\ Email: kirk.atkinson@wku.edu \\ USA \\ Ray Blankenship \\ Gordon Ford College of Business \\ Western Kentucky University \\ 1906 College Heights Blvd \\ Bowling Green, Kentucky 42101-1058 \\ Email: ray.blankenship@wku.edu \\ USA \\ Brady Crawford \\ Student Research Assistant \\ Gordon Ford College of Business \\ Western Kentucky University \\ 1906 College Heights Blvd \\ Bowling Green, Kentucky 42101-1058 \\ USA \\ Tucker S. Ramage \\ Student Research Assistant \\ Gatton Academy of Mathematics and Science \\ Western Kentucky University \\ 1906 College Heights Blvd \\ Bowling Green, Kentucky 42101-1058 \\ USA
}

\section{ABSTRACT}

Several class sections at a Midwestern, public university were instructed in basic data analytics concepts using $\operatorname{SimNet}^{\circledR}$ preparatory assignments with Microsoft Excel ${ }^{\circledR}$, additional instructional materials, and subsequent analytics projects. Performance on each analytics project was measured against performance on the preparatory Excel assignments as well as the student final course performance. The preparatory assignments prepared students for associated analytics projects as well as the final assessment.

\section{Introduction \& Literature Review \\ History of data analytics}

Analysis of data is perhaps as old as the collection of data. The methods change, driven by available technology and business need, but the basics of analysis remain constant. Simple comparisons of total revenues from year to year, examining median averages for housing prices, and tabulating the results of a marketing campaign, are all examples of how data historically helps decision-makers. Early analysis techniques aided by technology advancements include descriptive statistics as well as the use of spreadsheets like
VisiCalc $₫$, Lotus 1-2-3®, and most recently Microsoft Excel®. As the need for added value from the data collected emerged, so requires more sophisticated software tools and techniques. As the volume of data increased, added pressure was placed on analysts to move from simple historical analysis of data to predictive and even prescriptive analytics.

The available spreadsheet software witnessed innovations like scenario management, optimization tools, and pivot tables, often from third-party providers as in the case of Solver ${ }^{\circledR}$ for Excel. As the volume, variety, and velocity 
(Daniel, 2015) evolved, so did the need for the tools to handle the larger datasets, or Big Data, as it is so often referred to.

The need for qualified professionals to work as frontline business analysts exploded (cite) as organizations began to understand the need for additional data, the analysis of the data, and most importantly, the meaning of the data! Universities began to offer programs in data analytics, primarily at the graduate level. By 2015, the demand continued to outpace the production of qualified business data analysts (Zadeh, Schiller, Duffy, and Williams, 2018). Undergraduate programs were seemingly non-existent; one can only assume due to the perceived nature of the complexity of this type of analysis. According to the AACSB [Association to Advance Collegiate Schools of Business], a relatively small percentage of colleges of business offer an undergraduate-level data analytics program, but the transformation is already occurring ("Globalization of," 2011).

\section{Graduate programs}

Graduate programs in data analysis, data science, and data analytics are the norm in higher education. It may be surmised that analyzing data, and more importantly, the interpretation of the results of the analysis was traditionally deemed graduate level from a cognitive and experiential academic perspective.

\section{Undergraduate programs: rising quickly}

After attending an AACSB curriculum workshop in Tampa, Florida in June of 2016, it became apparent that the vast majority of programs currently offered was graduate in nature. The program implemented at our institution appeared to be an early adopter in terms of undergraduate programs. Certainly, one of the most significant obstacles faced was the recognition of Data Analytics as a discipline. One aspect of the issue has named the program appropriately. The program at this institution was initially called Business Informatics to appeal to the interdisciplinary nature of this field. This decision proved to be problematic as most prospective students and their parents did not recognize the term Informatics as intended. Even college placement officers and program advisors were often unaware of the nature of this nebulous topic (Jones, 2018), which is highly unfortunate given the increase in industry interest in this field.

Finance, accounting, marketing, management, and even economics were all well-recognized disciplines with established career paths.

After researching other potential program names, Business Data Analytics was selected. This selection was anything but the silver bullet to the name recognition issue. The marketing efforts to achieve name recognition were arduous. This was aided when several other major universities began offering undergraduate majors and certificates (Hill and Kline, 2017). This ushered in the entrance of Data Analytics as a defined discipline into the mainstream.

\section{The use of a business college service course}

The offering of any new major is typically difficult at any institution; a name change added complexity. The solution to this dilemma was to offer an undergraduate certificate in Data Analytics in addition to a major. Certificates are, at the time of this research, extremely well-valued by the marketplace, even more so than minors! The primary method of attracting certificate seekers, and in some cases, new majors, was to begin teaching basic data analytic concepts in a course required of all business majors. An AACSB accredited business school implies a core course, and in this case, Principles of Management Information Systems was selected. This course is aimed at sophomores, making the selection of a major a possibility early within their program of study. Also, for those already with a selected major, the certificate becomes an attractive credentialing. The certificate requires the principles course already mentioned, a statistics course, and four additional electives. These electives may be selected from several pre-approved 300- and 400-level courses that include courses in the Business Data Analytics major as well as numerous ones from other disciplines within the business school with an analytic focus. The certificate quickly grew and became the most popular on the entire campus, all other colleges inclusive. Additionally, the certificate proved to be a growth-enhancing tool for the major! Offering Business Data Analytics as a dual major attracts many new students who have already decided upon their major. When implementing a dual major, ensure that it is not a second major which adds many additional hours to the student's degree program; dual majors allow for some cross counting of upper-division coursework.

This study is intended to assess the effectiveness of using principles of management information systems course at a 4-year, public university located in the United States Midwest to instruct undergraduate college students in the basic principles of data analytics. For this research, effectiveness will be defined by this question:

R1-Do spreadsheet modeling assignments, in combination with tutorials, adequately prepare undergraduate business students for introductory-level data analytics projects?

\section{Methodology}

Principles of Management Information Systems courses remain quite common among AACSB accredited business colleges. This course is typically a requirement of all business majors and is the focal point of the introduction of data analytics concepts using Microsoft Excel ${ }^{\circledR}$ as the software tool. Several sections of this course are offered by different instructors; however, a single instructor performed this trial on two face-to-face sections and one online section. This research was conducted at a mid-sized, public university located in the Midwestern United States. Students were not pre-selected by delivery method and should be considered convenience samples as members of the course sections affected. The total 


\section{(C) Center for Promoting Education and Research (CPER) USA}

WWW.cpernet.org

number of students that participated in the combined course sections is 90 .

Microsoft Excel ${ }^{\circledR}$ was selected as the tool of choice primarily because of the popularity of this spreadsheet software among organizations and its usefulness to students in all disciplines. Four analytics projects were defined by the instructor and involved the construction of a model to solve basic business problems. This model construction was followed using both built-in, what-if analysis, and add-in tools. The projects were purposely vague in terms of defined written instructions, but examples of all required elements were demonstrated in class, and where applicable, provided as ondemand video tutorials to students, regardless of delivery method. Also, all projects provided a visual representation of the expected outcomes in PDF form to preserve project integrity. Each analytics project was assigned only after the completion of selected McGraw-Hill SimNet ${ }^{\circledR}$ spreadsheet assignments. These projects were specifically selected to assist students by providing the technical skills needed to complete each analytics project. The first few projects provide context and understanding for the first analytics assignment by building a basic spreadsheet model. Additionally, an entire lecture session was spent discussing and demonstrating examples of spreadsheet models. After the basic model was constructed and verified for proper functionality, additional Excel project assignments continued to build on the skills needed for each successive analytics project. There was a total of three analytics projects after the initial model build assignment.

Analytics project 1 included the business model that was closely monitored and with any recommended corrections made before proceeding. This project included the use of what-

if tools, Goal Seek, Scenario Manager, one-variable and twovariable data tables, some basic charts, and finally a pivot table.

Analytics project 2 includes four [4] Solver problems and was strongly correlated to overall student performance and was statistically significant to Excel cases 6 through 9 which were preparatory for this topic.

Analytics project 3 introduced the use of larger datasets. A 7,000-row dataset was provided. The students were asked to create several pivot tables and associated pivot charts.

\section{There were 90 scores used.}

Pearson correlations were run against the Excel preparatory SimNet ${ }^{\circledR}$ activities and the associated Analytics Projects, Excel projects 1 through 5 against the first analytics projects, and Excel projects 6 through 9 for the second and third analytics projects.

Additionally, an ANOVA was performed using aggregated mean scores to determine the significance between the Excel preparatory assignments and the analytics projects versus the student final course performance.

\section{Results}

The data analytics project scores of students from all three (3) sections were analyzed by performing the Pearson Correlation. The aggregated outcomes of analytics project scores were compared to the overall student performance in the course and the performance during the preparatory McGrawHill SimNet ${ }^{\circledR}$ spreadsheet activities related to skillsets required.

The first five Excel SimNet ${ }^{\circledR}$ activities and Analytics Projects 1 and 2 are significant.

Table 1-SimNet ${ }^{\circledR}$ Activities vs Corresponding Analytics Project

\begin{tabular}{|c|c|c|c|c|}
\hline & & $\begin{array}{c}\text { Analytics } \\
\text { Project } 1 \\
\end{array}$ & $\begin{array}{l}\text { Analytics } \\
\text { Project } 2\end{array}$ & $\begin{array}{l}\text { Analytics } \\
\text { Project } 3\end{array}$ \\
\hline \multirow[t]{3}{*}{$\begin{array}{l}\text { Excel 1- } \\
5\end{array}$} & $\begin{array}{l}\text { Pearson } \\
\text { Correlation }\end{array}$ & $.838^{* *}$ & $.556^{* *}$ & $.299^{* *}$ \\
\hline & Sig. (2-tailed) & 0.000 & 0.000 & 0.004 \\
\hline & $\mathrm{N}=90$ & & & \\
\hline \multirow[t]{3}{*}{$\begin{array}{l}\text { Excel } 6 \text { - } \\
9\end{array}$} & $\begin{array}{l}\text { Pearson } \\
\text { Correlation }\end{array}$ & $.709^{* *}$ & $.725^{* *}$ & -0.053 \\
\hline & Sig. (2-tailed) & 0.000 & 0.000 & 0.621 \\
\hline & $\mathrm{N}=90$ & & & \\
\hline
\end{tabular}

**. Correlation is significant at the 0.01 level (2-tailed).

*. Correlation is significant at the 0.05 level (2-tailed).

Analytics project results were also compared to the student performance in the course [Table 1]. This includes the preparatory SimNet ${ }^{\circledR}$ activities and the final exam which is Excel based. Analytics project 3, which is intended to be a capstone activity, was not significant.
Table 2 depicts the results of Pearson Correlation results for student final performance, the Excel final examination, the aggregation of mean scores for Excel preparation activities 1 through 5 and 6 through 9, respectively. 
Table 2-SimNet ${ }^{\circledR}$ Activities vs Final Student Course and Excel Exam Performance

\begin{tabular}{|c|c|c|c|c|c|}
\hline & & $\begin{array}{l}\text { Final } \\
\text { Performance }\end{array}$ & $\begin{array}{l}\text { Excel } \\
\text { Exam }\end{array}$ & Excel 6 - 9 & Excel $1-5$ \\
\hline \multirow{3}{*}{$\begin{array}{l}\text { Final } \\
\text { Performance }\end{array}$} & Pearson Correlation & & $.857^{* * *}$ & $.924^{* *}$ & $.855^{* *}$ \\
\hline & \multirow{2}{*}{$\begin{array}{l}\text { Sig. (2-tailed) } \\
N=90\end{array}$} & & 0.000 & 0.000 & 0.000 \\
\hline & & & & & \\
\hline \multirow[t]{2}{*}{ Excel Exam } & Pearson Correlation & $.857^{* *}$ & & $.722^{* *}$ & $.676^{* *}$ \\
\hline & Sig. (2-tailed) & 0.000 & & 0.000 & 0.000 \\
\hline
\end{tabular}

$\mathrm{N}=90$

**. Correlation is significant at the 0.01 level (2-tailed).

The final performance is the final accumulated point analytics projects were also covered on the exam. Table 3 total out of a possible of 1,000 points. The Excel final exam depicts the results of an ANOVA including the Excel activities covered most topics covered in the Excel 1 through 9 and all three analytics projects. activities, with a few exceptions. Numerous concepts from

\section{Table 3 - Preparatory Cases and Analytics Projects vs Final}

\section{Performance}

\begin{tabular}{l|r|l} 
& \multicolumn{1}{|c|}{ F } & \multicolumn{1}{c}{ Sig. } \\
\hline Excel cases 1 - 5 & 7.334 & $0.000^{* *}$ \\
\hline Excel cases 6 - 9 & 3.871 & $0.003 * *$ \\
\hline Analytics Project 1 & 17.775 & $0.000^{* *}$ \\
\hline Analytics Project 2 & 64.646 & $0.000^{* *}$ \\
\hline Analytics Project 3 & 0.886 & 0.652
\end{tabular}

**. Correlation is significant at the 0.01 level (2-tailed).

Only the final analytics project indicated no significance as it relates to the final student performance. All other preparatory Excel cases and analytics projects were significant.

\section{Discussion}

Data analytics, once a relatively unknown discipline among prospective college students and their parents, quickly transitioned into the fast lane of popular college majors. Many educators and administrators are recognizing the need to integrate data analytics into every business discipline and many in the liberal arts.

The approach for the subject of this research, an AACSB business school within a public institution, is already integrating data analytics skills throughout every discipline (Henry and Venkatraman, 2015). As late as 2015, the major then known as Business Informatics, eventually renamed to Business Data Analytics, remained a mystery to most students, parents, and even academic advisors. Through marketing efforts, and the advent of several other top-tier universities' introductions of a major in Data Analytics, the popularity of the discipline is steadily growing. Within the business college, the Principles of Management Information Systems course was selected for an interdisciplinary study of the introduction of data analytics basics to students. For one, all business majors must complete this course. Secondly, students from outside the business school routinely take this course as an elective. This further reinforces the interdisciplinary role of data analytics. Perhaps most importantly, the course is considered at the sophomore-level which is a sound approach to educate students that are; considering a major change, still undecided, or searching for a dual-major to complement their first choice. This course is also the ideal point in most student's programs of study to explain the importance of these skills in every discipline.

The lack of written instruction simulated analytics work in a real-life workplace. The instructor remained available to respond to specific questions but avoided generalized "how-to" responses. The guided construction of a separate spreadsheet model is recommended as preparatory work. This would entail working through a complete spreadsheet model with students to expose them to the concepts and skills expected of them to learn. Many students struggled with this assignment and because it is crucial to complete it correctly before the first analytics project, guided instruction is recommended. 


\section{(C) Center for Promoting Education and Research (CPER) USA}

WWW.cpernet.org

The results indicated that there is a strong, and statistically significant correlation between the Excel preparatory activities and the first two analytics projects. Interestingly, the final analytics project was not statistically significant to the student's final performance. It is not clear whether this comprehensive project was assigned too late in the term or if the assignment itself is ineffective. Assignments late in the term often lack the participation as earlier ones because students are aware of points required to achieve the grade that satisfies their needs. The heavier weighting of this project may help. If the project lacks effectiveness, then additional requirements may need to be added as opposed to allowing students latitude. As previously mentioned, there seems to be a stigma surrounding the field of data analytics which suggests it is too complicated to offer at the undergraduate level, explaining why most of these programs are graduate level. These results indicate undergraduate students are capable of learning and understanding topics surrounding the field of business data analytics. Assuming this stance is valid, there is a need for more universities to offer majors and certificates to accommodate industry needs. As more undergraduate students are introduced to the material, there will be significantly less confusion and ignorance surrounding the field of study. Business data analytics will quickly become one of the leading majors in collegiate education. The simple truth is that information science and business data analytics are highly relevant and regarded degrees for many industries. It is and will continue to be, highly demanded in the workforce. For this reason, there is a definite need to expand opportunities in this area for undergraduates.

\section{Student Researchers Perspectives}

Insert Tucker's and Brady's observations here

\section{Limitations}

This research is limited for several reasons. This material was taught using this methodology for the first time. Although there were several sections of the course available, only three [3] were selected and taught by the same instructor. Secondly, the subjects were not randomly sampled, convenience sampling was utilized.

\section{Conclusions}

The research indicates sufficient evidence to continue using the approach with enhancements, especially related to the final analytics project. The future direction will also include additional sections with various instructors. Comparisons of additional sections and between instructors may assist in recommendations for improvements in the methodology and types of project activities.

\section{References}

Asamoah, D., Sharda, R., Hassan Zadeh, A., \& Kalgotra, P. (2017). Preparing a Data Scientist: A Pedagogic Experience in Designing a Big Data Analytics Course. Decision Sciences Journal of Innovative Education, 15(2), 161190.

Daniel, B. (2015). Big Data and analytics in higher education: Opportunities and challenges. British Journal of Educational Technology, 46(5), 904-920.

Globalization of Management Education: Changing International Structures, Adaptive Strategies, and the Impact on Institutions Report of the AACSB International Globalization of Management Education Task Force. (First Edition, 2011). 43-45, Retrieved from https://www.aacsb.edu/-/media/aacsb/publications/research-reports/aacsb-globalization-of-management-education-taskforce-report-2011.ashx?la=en

Hill, S., \& Kline, D. (2017). Teaching "Big Data" in a Business School: Insights from an Undergraduate Course in Big Data Analytics. Journal of the Academy of Business Education, 18, 175-185.

Jones, Kyle. "Advising the Whole Student: eAdvising Analytics and the Contextual Suppression of Advisor Values." Education and information technologies 24.1 (2018): 437-458. Web.

Zadeh, A., Schiller, S., Duffy, K., \& Williams, J. (2018). Big Data and the Commoditization of Analytics: Engaging First-Year Business Students with Analytics. E-Journal of Business Education and Scholarship of Teaching, 12(1), 120-137. 